\title{
USAHA PERIKANAN TANGKAP DI PULAU SEBATIK DALAM MENDUKUNG SKPT SEBATIK
}

\section{Fisheries Bussiness in Sebatik Island to Support the SKPT Sebatik}

\author{
*Asnawi ${ }^{1}$, Firsta Kusuma Yudha ${ }^{2}$, dan Umi Muawanah ${ }^{3}$ \\ ${ }^{1}$ Politeknik Ahli Usaha Perikanan \\ JI. Aup Bar. JI. Raya Pasar Minggu, Kota Jakarta Selatan, DKI Jakarta 12520, Indonesia \\ ${ }^{2}$ Fakultas Perikanan dan IImu Kelautan, IPB University \\ Jl. Raya Dramaga Kampus, IPB Dramaga Bogor, 16680 Jawa Barat, Indonesia \\ ${ }^{3}$ Balai Besar Riset Sosial Ekonomi Kelautan dan Perikanan \\ Gedung BRSDM KP I Lt. 4, Jalan Pasir Putih Nomor 1 Ancol Timur, Jakarta Utara, Indonesia \\ Diterima tanggal: 3 April 2020; Diterima setelah perbaikan: 10 April 2021; \\ Disetujui terbit: 25 Juni 2021
}

\begin{abstract}
ABSTRAK
Pembangunan Sentra Kelautan dan Perikanan Terpadu (SKPT) Sebatik merupakan upaya pemerintah membangun perikanan di pulau terluar Indonesia. Penelitian ini bertujuan mempelajari kondisi usaha perikanan di Sebatik, sebagai bahan masukan dalam pengelolaan dan memajukan SKPT Sebatik. Penelitian ini dilakukan pada tahun 2018 di Sebatik menggunakan data primer primer dan sekunder. Data primer dikumpulkan melalui survey dengan responden yang dipilih secara purposif dan dengan teknik snowball sampling, dan melalui Focus Group Discussion (FGD). Data sekunder diperoleh dari studi literatur pada dokumen-dokumen terkait. Data yang dikumpulkan kemudian diolah menjadi informasi kualitatif menggunakan pendekatan tematik Ada lima temuan pokok dari penelitian ini. Pertama: terjadi tingkat pemanfaatan sumber daya perikanan melebihi batas untuk (i) pelagis besar, (ii) rajungan dan (iii) cumi-cumi akibat penggunaan alat tangkap trawl oleh nelayan Tawau pada waktu lampau. Kedua: Sebagian besar Ikan hasil tangkapan di Sebatik didaratkan menggunakan motor tempel dengan kapasitas 0-5 GT. Ketiga; terdapat lima jenis ikan bernilai ekonomis tinggi yang termasuk jenis udang dan moluska. Keempat: pemasaran ikan dari Sebatik dicirikan oleh adanya ikatan sosial ekonomi antara pedagang pengumpul, pedagang besar, dan agen di Tawau Malaysia. Kelima: kondisi-kondisi tersebut membuat pencatatan ekspor menjadi kurang baik dan dapat beresiko pada keberlanjutan sumber daya perikanan di wilayah itu. Berdasar hal ini, langkah strategis yang dapat direkomendasikan adalah penguatan integrasi aktor-aktor usaha perikanan tangkap di Sebatik ke dalam skema SKPT untuk memudahkan pencatatan ekspor hasil perikanan dari Sebatik ke Tawau Malaysia.
\end{abstract}

Kata Kunci: penangkapan ikan; Pulau Sebatik; usaha perikanan; pemanfaatan ikan; potensi perikanan

\section{ABSTRACT}

The Sebatik Integrated Marine and Fisheries Center (SKPT Sebatik) built to develop the fisheries sector in Indonesia's outermost islands. This study aimed to asses the fisheries business condition in Sebatik as recommendation for the management and advancement of SKPT Sebatik. The research was conducted in 2018 in Sebatik based on primary and secondary data. Primary data were collected through surveys with purposive and snowball sampling, and Focus Group Discussion (FGD). Secondary data were obtained from literature studies of relevant documents. The data were processed into qualitative information with thematic approach. There are five key findings of the research. First, the utilization rate of fisheries resources has exceeded its maximum level for (i) large pelagic fish, (ii) crabs, and (iii) squids as a result of the past trawl fishing by Tawau fishers. Second, most of the catches in Sebatik are landed using outboard motors of 0-5 GT. Third, there are five species of fish classified as shrimp and molluscs that bring a high economic value. Fourth, there is a social economic relationship among traders, wholesalers and agents in Tawau Malaysia in fish marketing from Sebatik. Fifth, such conditions resulted in a poor record of fish export and threaten the sustainability of fish resources in the area. Based on these findings, this study recommend to policy makers reinforce the integration of capture fisheries business actors in Sebatik into SKPT to facilitate the record of fishery product export from Sebatik to Tawau, Malaysia.

Keywords: fishing; Sebatik Island; fisheries business; fish utilization; fishery potential 


\section{PENDAHULUAN}

Interaksi sosial dan ekonomi antara warga Malaysis adan Indonesia di Pulau Sebatik sangat kuat sejak dulu. Hal ini dimungkinkan karena Pulau Sebatik merupakan salah satu pulau kecil terluar di Indonesia yang pulaunya terbagi menjadi dua wilayah yaitu sebagian wilayah Negara Indonesia, sebagian wilayah Negara Malaysia. Pada saat yang sama, posisi Pulau Sebatik ini berseberangan langsung dengan Tawau, yaitu salah satu kota di Malaysia. Tawau mempunyai pengaruh yang cukup tinggi terhadap perekonomian warga Indonesia di Pulau Sebatik (Setiawan, Bandiyono, Sudiyono \& Soekarni, 2011). Pulau Sebatik terletak $5 \mathrm{~km}$ dari Tawau (Siburian, 2012). Pada saat yang sama, Pulau Sebatik memiliki sumber daya alam yang besar seperti hasil-hasil pertanian dan perikanan. Hal ini menyebabkan tingginya interaksi yang berlangsung antara kedua negara melalui jalur Sebatik-Tawau (Ghafur, 2016).

Interaksi sosial dan ekonomi antar kedua negara telah menggerakkan ekonomi di Pulau Sebatik melalui peredaran bahan-bahan makanan pokok, pakaian dan teknologi. Sebagai gantinya, warga Sebatik menjual hasil pertanian dan perikanan. Akan tetapi, interaksi ini juga mempunyai beberapa masalah (Setiawan et.al. (2011)). Penelitian Setiawan (2011) menyatakan bahwa interaksi tersebut telah membuat ketergantungan ekonomi warga Sebatik terhadap Tawau. Pada tahun 2016, Pemerintah Indonesia mencanangkan program penguatan industri perikanan di pulaupulau terluar termasuk Pulau Sebatik yang berbatasan dengan Malaysia. Program ini mempunyai tujuan pembangunan ekonomi dan peningkatan pembangunan ekonomi perikanan. Penelitian ini bertujuan untuk mendukung program penguatan industri perikanan di Pulau Sebatik dengan mengintegrasikan aktor-aktor ekonomi lokal ke dalam kawasan industri perikanan yang dibangun oleh KKP. Kawasan ini disebut Sentra Kelautan dan Perikanan Terpadu (SKPT) Sebatik.

Permasalahan usaha perikanan di Pulau Sebatik antara lain: (1) Sarana dan prasarana pendukung pengembangan bisnis perikanan di Pulau Sebatik masih terbatas (Shafitri et al.,2020). Armada perikanan tangkap mayoritas adalah perikanan tangkap kecil yaitu 2.216 unit motor tempel sekitar $86 \%$ dan sisanya sekitar 13,6\% kapal motor. Prasarana pendukung usaha perikanan seperti pelabuhan perikanan, cold storage, pabrik es dan perbekalan belum berfungsi dengan baik. Minimnya sarana dan prasarana penunjang menyebabkan para nelayan kalah bersaing dengan para pedagang dan nelayan dari Tawau (Ghafur 2016). Peningkatan pembangunan dan pengadaan sarana prasarana di Pulau Sebatik sangat dibutuhkan untuk kemajuan bisnis perikanan di Sebatik; (2) Hubungan antar pedagang usaha perikanan besar di Sebatik dan di Tawau ini sangat kuat sehingga penguasaan aset dan sumber modal dalam bisnis ini dikuasai oleh sekelompok orang (Solihin et al. 2011); dan (3) Pengembangan bisnis perikanan di Sebatik menghadapi kekurangan tenaga kerja. Masyarakat lebih senang bekerja di Tawau, sebagai pekerja pada kapal trawl, supir, pekerja kilang, penjaga toko, buruh di perkebunan dan pekerjaan lainnya. Hal ini dikarenakan Sebatik masih jauh tertinggal dibanding daerah lainnya, sedangkan Tawau sudah melangkah maju dalam ekonomi dan infrastruktur, sehingga upah dan kesejahteraan di Tawau lebih menjanjikan (Ghafur 2016).

Perikanan merupakan salah satu sektor unggulan di Pulau Sebatik dalam mengejar ketimpangan perekonomian tersebut (Nurisnaeny, 2012). Tujuan penelitian ini yaitu: (1) memahami kondisi perikanan di Sebatik; (2) mempelajari struktur perikanan tangkap di Pulau Sebatik, (3) menganalisis usaha perikanan tangkap di Pulau Sebatik. Hasil penelitian dapat menjadi bahan acuan atau referensi untuk menentukan kebijakan perikanan dalam mendukung pembangunan infrastruktur di Pulau Sebatik yaitu SKPT Sebatik. Pembangunan infrastruktur merupakan pembangunan yang menyesuaikan dengan kebutuhan masyarakat (Hadi, 2009).

Kajian ini dilakukan di SKPT Sebatik, tepatnya di Pulau Sebatik pada tahun 2018. Metode riset bersumber data primer dan data sekunder. Survei menggunakan purposive sampling dan snowball sampling dengan 135 responden. Responden terdiri dari 70 responden nelayan moter tempel, 50 responden nelayan kapal motor, 10 responden pedagang pengumpul dan 5 responden pedagang besar. Data primer diperoleh dari penggalian data menggunakan perangkat kuesioner dan Focus Group Discussion (FGD) atau diskusi kelompok terarah untuk mendapatkan informasi yang lebih detail dan sesuai dengan kondisi sebenarnya. Selanjutnya, data dianalisis menggunakan metode deskriptif tematik untuk mengidentifikasi, dan mengkaji usaha perikanan tangkap di Pulau 
Sebatik. Poerwandari (2005) menyatakan bahwa pendekatan tematik merupakan suatu proses yang digunakan dalam mengolah informasi kualitatif.

\section{KONDISI STOK SUMBER DAYA PERIKANAN}

Jumlah tangkapan diperbolehkan (JTB) atau Total Allowable Catch (TAC) dari Kabupaten Nunukan dapat dihitung dengan menggunakan perbandingan panjang garis pantai Kabuten Nunukan terhadap total panjang garis pantai WPP 716. Secara umum, tingkat pemanfaatan ikan pelagis besar, rajungan dan cumi-cumi telah menunjukkan tingkat pemanfaatan yang fully exploited dan over exploited. Di Sebatik sendiri, salah satu penyebab tingkat pemanfaatan yang melebihi batas dari ketiga sumber daya tersebut (ikan pelagis besar, rajungan dan cumi-cumi) disebabkan adanya penggunaan alat tangkap trawl oleh nelayan Tawau Malaysia pada waktu lampau. Meskipun sejak tahun 2015 telah ada pelarangan penangkapan ikan oleh kapal asing, ketiga sumber daya tersebut belum dapat kembali optimal dimanfaatkan oleh nelayan di Pulau Nunukan dan Sebatik karena kemampuan sumber daya perikanan tidak dapat cepat pulih. SKPT Sebatik berfungsi sebagai pintu keluar masuknya hasil dan produksi perikanan di Pulau Sebatik.
Pengelolaan sumber daya perikanan laut perlu dilakukan dengan prinsip dan kaidah yang benar. Esensi pengelolaan sumber daya perikanan adalah mencari keseimbangan antara eksploitasi dan kemampuan reproduksi atau daya pulih sumber daya (Nikijuluw, 2002). Dengan demikian, pemanfaatan pusat industri perikanan di SKPT Sebatik secara berkelanjutan perlu diberlakukan untuk menghindari adanya IUU Fishing di Sebatik dan sekitarnya.

\section{PERKEMBANGAN PEMANFAATAN SUMBER DAYA IKAN DI SEBATIK}

Ikan hasil tangkapan di Pulau Sebatik sebagian besar didaratkan menggunakan motor tempel ukuran 0-5 GT. Pada tahun 2016 jumlah armada penangkapan ikan mencapai 1.412 unit kapal penangkap ikan (BPS Kabupaten Nunukan, 2017). Di Kabupaten Nunukan terdapat banyak jenis pelabuhan yang menjadi sentra perhubungan laut, di antaranya pelabuhan umum, penyeberangan ferry, speedboat, pelabuhan pendaratan ikan (PPI), terminal khusus, dan pelabuhan angkatan laut (Radiarta, Erlania, Haryadi \& Rosdiana, 2016).

Armada penangkapan ikan yang banyak digunakan pada SKPT Sebatik adalah motor tempel 0-5 GT I sebanyak $83 \%$, dan $16 \%$ merupakan

Tabel 1. Potensi Perikanan Kabupaten Nunukan Berdasarkan Kuota JTB WPP 716. Table 1. Potential Fisheries in Nunukan Regency based on TAC Quota in FMA 716.

\begin{tabular}{|c|c|c|c|c|}
\hline Jenis Ikan/ Fish Type & $\begin{array}{l}\text { Potensi/ } \\
\text { Potency (ton) }\end{array}$ & $\begin{array}{l}\text { JTB/ TAC } \\
\text { (ton) }\end{array}$ & $\begin{array}{l}\text { Tingkat Pemanfaatan/ } \\
\text { Utilization Rates }\end{array}$ & $\begin{array}{l}\text { JTB Nunukan/ } \\
\text { Nunukan TAC } \\
\text { (ton) }\end{array}$ \\
\hline Pelagis Kecil/ Small Pelagic & 222,946 & $178,356.8$ & Menengah/ Moderate & $121,282,624$ \\
\hline Pelagis Besar/ Big Pelagic & 154,329 & $123,463.2$ & $\begin{array}{l}\text { Sepenuhnya Dieksploitasi/ } \\
\text { Fully-exploited }\end{array}$ & $83,954,976$ \\
\hline Ikan Demersal/ Demersal Pelagic & 34,650 & 27,720 & Menengah/ Moderate & $1,884.96$ \\
\hline Ikan Karang/ Reef Fish & 54,194 & $43,355.2$ & $\begin{array}{l}\text { Dieksploitasi Berlebihan/ } \\
\text { Over-expoited }\end{array}$ & $29,481,536$ \\
\hline Udang Penaid/ Penaid Shrimp & 8,465 & 6,772 & $\begin{array}{l}\text { Sepenuhnya Dieksploitasi/ } \\
\text { Fully-exploited }\end{array}$ & 460,496 \\
\hline Lobster/ Lobsters & 685 & 548 & $\begin{array}{l}\text { Dieksploitasi Berlebihan/ } \\
\text { Over-expoited }\end{array}$ & 37,264 \\
\hline Kepiting/Crab & 1,969 & $1,575.2$ & $\begin{array}{l}\text { Sepenuhnya Dieksploitasi/ } \\
\text { Fully-exploited }\end{array}$ & $1,071,136$ \\
\hline Rajungan/ Swimming Crab & 424 & 339.2 & $\begin{array}{l}\text { Dieksploitasi Berlebihan/ } \\
\text { Over-expoited }\end{array}$ & 230,656 \\
\hline Cumi-cumi/ Squid & 1,103 & 882.4 & $\begin{array}{l}\text { Dieksploitasi Berlebihan/ } \\
\text { Over-expoited }\end{array}$ & 600,032 \\
\hline Jumlah/Total & 478,765 & 383,012 & & \\
\hline
\end{tabular}

Sumber: Masterplan SKPT Nunukan, DJPT 2014/Source: SKPT Nunukan Masterplan, DJPT 2014. 
kapal motor 5-10 GT. Kapal dengan motor tempel di Pulau Sebatik dapat dijumpai di Kecamatan Sebatik (26\%), di Kecamatan Sebatik Timur (50\%), masing-masing di Kecamatan Sebatik Utara dan Kecamatan Sebatik Barat (11\%) serta 1\% di Kecamatan Sebatik Tengah. Hal ini menunjukkan adanya dominasi nelayan kecil, dimana nelayan kecil digolongkan ke dalam perikanan skala kecil yang dianggap banyak berkontribusi pada ekonomi masyarakat (Mansur, Muazzin, Yani, \& Sulaiman,2017).

Armada perikanan di kawasan SKPT Sebatik menggunakan 9 (sembilan) jenis alat tangkap ikan, yaitu dogol, jaring insang tetap, jaring angkat, jaring insang hanyut, jaring tiga lapis (tramel net), rawai hanyut, jaring insang lingkar, bagan tancap dan rawai tetap. Husin (2018) mengungkapkan bahwa alat tangkap yang digunakan oleh nelayan sebatik adalah Jaring Tiga Lapis, Bagan Tancap, Pukat Lobster, Pukat Bawal, Pukat Tenggiri dan Pukat Hela. Alat tangkap yang paling banyak dipakai adalah jaring insang hanyut dan jaring tiga lapis (Gambar 2). Penggunaan alat tangkap bagan dapat dijadikan salah satu strategi alternatif dalam permasalahan illegal fishing di wilayah perbatasan. Solihin, Imron, \& Wahyono (2012) menyatakan bahwa didirikannya bagan di wilayah perbatasan dapat mengurangi kegiatan pelanggaran perbatasan kawasan perairan oleh kapal-kapal nelayan dari negara lain.

Alat tangkap jaring tiga lapis digunakan oleh nelayan di Kecamatan Sebatik, Kecamatan Sebatik Timur, dan Kecamatan Sebatik Barat.
Sementara alat tangkap jaring insang hanyut digunakan oleh nelayan di Kecamatan Sebatik Timur, di Kecamatan Sebatik Utara, dan di Kecamatan Sebatik Barat. Alat tangkap dogol lebih banyak dipakai di Kecamatan Sebatik Barat, dan di Kecamatan Sebatik. Jaring insang tetap hanya digunakan oleh nelayan di Kecamatan Sebatik Timur, dan Kecamatan Sebatik Barat. Daerah penangkapan dogol serupa dengan alat tangkap purseseine, yaitu mulai dari perairan dangkal dipinggir pantai, sampai laut dalam (Mirnawati, Nelwan \& Zainuddin, 2019). Sementara, bagan tancap terpusat di Kecamatan Sebatik, dan Kecamatan Sebatik Timur. Hasil tangkapan dari penggunaan alat tangkap bagan pada umumnya adalah ikan teri, dan cumi-cumi (Najamuddin, Hajar \& Sarira, 2017).

Penggunaan berbagai alat tangkap tersebut untuk menangkap ikan pelagis kecil, ikan karang, dan ikan demersal. Jenis ikan yang tertangkap antara lain ikan arut, bawal, cakalang, senangin, puput, putih, sebelah, tenggiri, talang, tude, kerapu, kakap, dan udang. Total produksi ikan di Sebatik pada tahun 2016 menurut BPS Kabupaten Nunukan (2017) adalah sebesar 3.041 ton.

Pendaratan ikan pada kawasan SKPT Sebatik diharapkan berasal dari nelayan yang tinggal di Kecamatan Sebatik (44\%), Kecamatan Sebatik Timur (36\%), Kecamatan Sebatik Utara (15\%), Kecamatan Sebatik Tengah (2\%), dan Kecamatan Sebatik Barat (4\%). Nelayannelayan tersebut menangkap ikan pada daerah

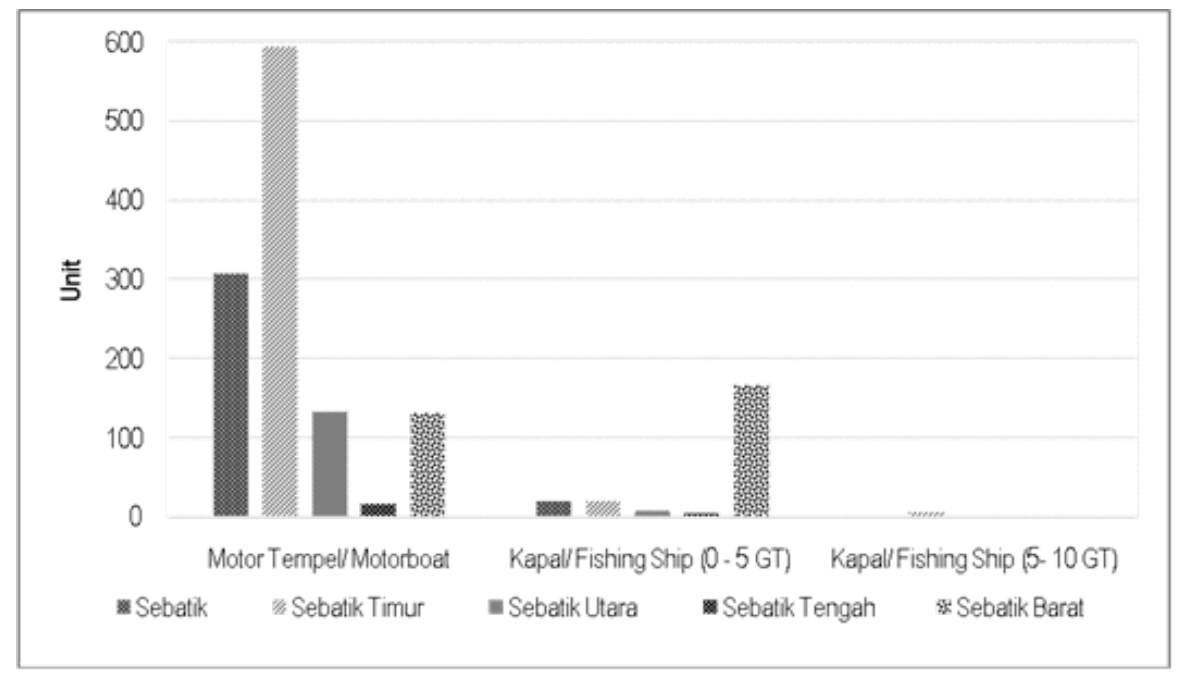

Gambar 1. Jumlah Armada Kapal Perikanan di Pulau Sebatik. Figure 1. Number of Fishing Vessels in Sebatik Island.

Sumber: Dinas Kelautan dan Perikanan Kab Nunukan, Statistik Perikanan Tangkap 2015/ Source: Nunukan Regency Maritime Affairs and Fisheries, Capture Fisheries Statistics 2015 


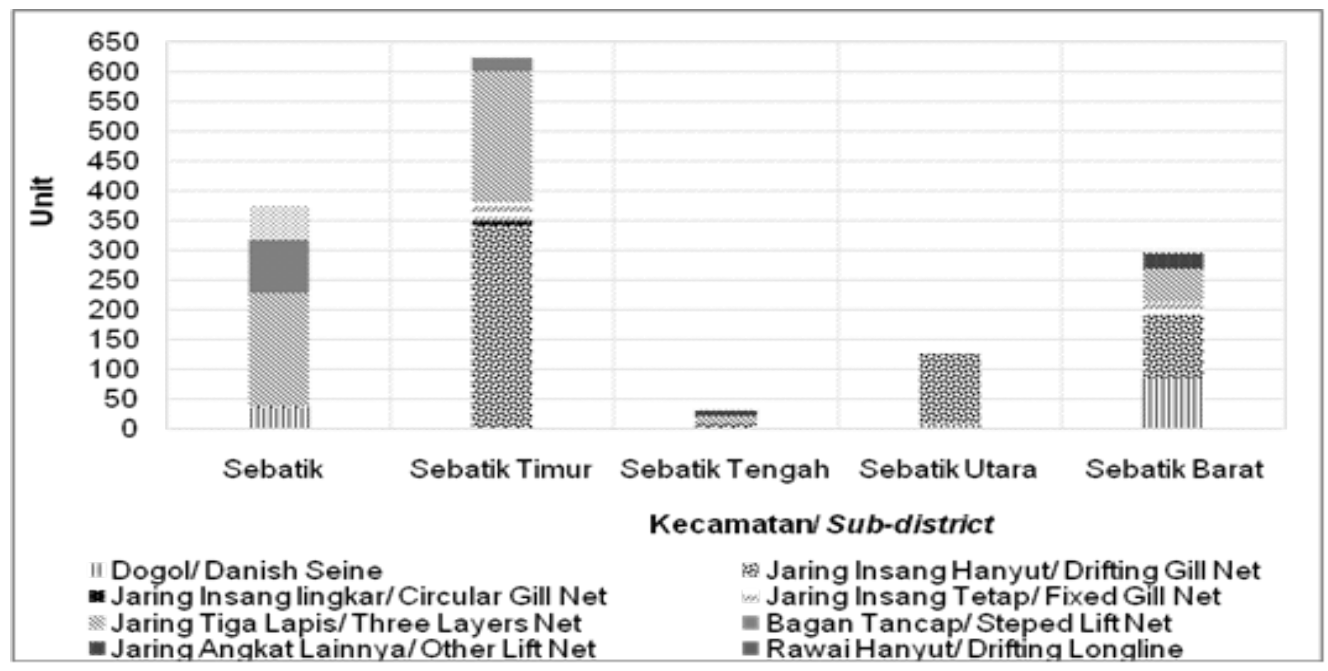

Gambar 2. Karakteristik Alat Penangkap Ikan di Pulau Sebatik.

Figure 2. Characteristics of Fishing Equipment on Sebatik Island.

Sumber: Dinas Kelautan dan Perikanan Kab Nunukan, Statistik Perikanan Tangkap 2015/

Source: Nunukan Regency Maritime Affairs and Fisheries, Capture Fisheries Statistics 2015

penangkapan ikan di perairan Pulau Sebatik sejauh 4-20 mil ke arah laut, pada perairan Ambalat, perairan karang Unarang, sampai ke perairan Tarakan dan perairan Pulau Bunyu (Gambar 3).

Waktu penangkapan ikan oleh nelayan di sekitar SKPT Sebatik dibedakan menjadi dua, yaitu trip harian (one day fishing), dan trip penangkapan mingguan. Nelayan yang melakukan penangkapan harian memanfaatkan pasang surut air harian untuk pergi ke laut, sedangkan nelayan mingguan hanya dapat melaut dua kali dalam satu bulan, terutama pada saat air pasang.
Alat tangkap bagan tancap di sekitar perairan Pulau Sebatik dapat digunakan sepanjang tahun. Kegiatan penangkapan ikan tergantung pada kondisi sumber daya di daerah penagkapan ikan dan sangat bergantung pada musim penangkapan (Juzmi, Triarso \& Fitri, 2017).

\section{BIAYA PENANGKAPAN IKAN DI PULAU SEBATIK KABUPATEN NUNUKAN}

Total biaya penangkapan ikan per trip sebesar 2,65 juta rupiah terdiri dari biaya operasional, biaya perbekalan melaut, dan biaya

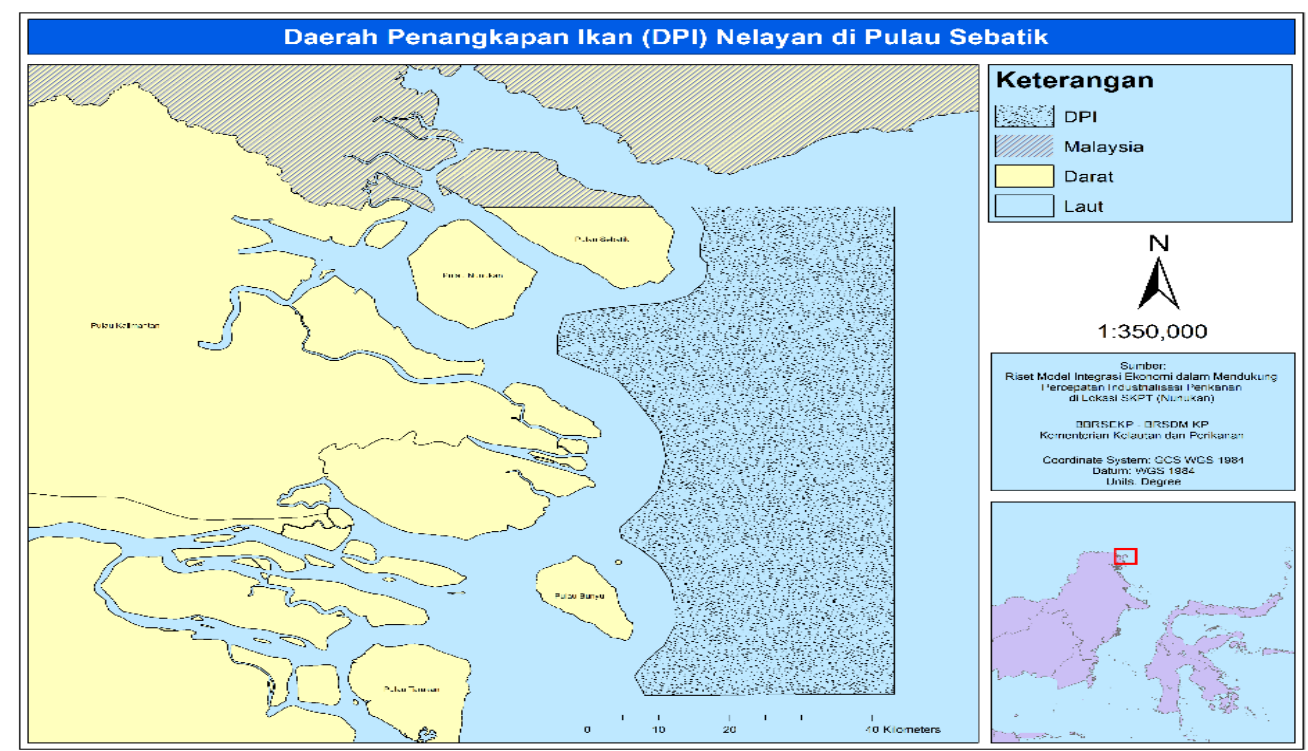

Gambar 3. Daerah Penangkapan Ikan Nelayan Pulau Sebatik.

Figure 3. Fishing area in Sebatik Island.

Sumber: Hasil Wawancara Diolah/Source: Interview Results Processed. 
operasional lainya. Dari total biaya tersebut, $82 \%$ atau senilai 2,17 juta rupiah digunakan untuk biaya operasional, yaitu sebesar $43 \%$ atau senilai 1,16 juta rupiah untuk pembelian solar dan bensin/premium; sebesar $12 \%$ atau senilai 319 ribu rupiah untuk pembelian es balok; dan $18 \%$ atau senilai 475 ribu rupiah untuk pembelian umpan. Sisanya sebesar $14 \%$ atau senilai 363 ribu rupiah untuk biaya perbekalan melaut, dan $4 \%$ atau senilai 120 ribu rupiah untuk biaya operasional lainnya (Tabel 2). Menurut Mira, Solihin \& Tajerin (2017) bahwa ada beberapa permasalahan utama dalam peningkatan ekonomi wilayah perbatasan, yaitu produktivitas perikanan tangkap dan budi daya yang rendah, maraknya illegal fishing, dan lemahnya peran kelembagaan ekonomi.

\section{PENDAPATAN NELAYAN DI PULAU SEBATIK KABUPATEN NUNUKAN}

Hasil usaha perikanan tangkap di Pulau Sebatik Kabupaten Nunukan dapat dikelompokkan menjadi kelompok ikan pelagis, kelompok ikan demersal, serta kelompok udang dan kepiting. Salah satu jenis udang yang menjadi hasil tangkapan nelayan di Kabupaten Nunukan adalah udang windu. Sebaran udang windu jenis Panaeus monodon di Indonesia ditemukan di perairan Aceh Timur, Laut Jawa, Timur Kalimantan, perairan

Tabel 2. Rata-Rata Biaya Penangkapan Ikan Trip Terakhir di Pulau Sebatik Kabupaten Nunukan Tahun 2018.

Table 2. The Average Cost of Catching the Last Trip on Sebatik Island, Nunukan Regency, 2018.

\begin{tabular}{|c|c|c|c|c|}
\hline No. & Jenis Biaya/Cost Types & $\begin{array}{c}\text { Volume (Unit)/ } \\
\text { Volumes } \\
\text { (Units) }\end{array}$ & $\begin{array}{c}\text { Harga per } \\
\text { Satuan (Rp)/ } \\
\text { Price per Unit } \\
\text { (IDR) }\end{array}$ & $\begin{array}{c}\text { Nilai Rata-Rata } \\
\text { Biaya (Rp)/ Cost } \\
\text { Average Value } \\
\text { (IDR) }\end{array}$ \\
\hline A. & Biaya Operasional/ Operation Cost & & & $2,166,000$ \\
\hline 1 & Solar/Solar & 125 & 7 & 516 \\
\hline 2 & Bensin/Pertalite & 70 & 9 & 648 \\
\hline 3 & Minyak Tanah/Kerosene & 3 & 38 & 52 \\
\hline 4 & Pelumas/Lubricant & 3 & 30 & 80 \\
\hline 5 & Es balok//ce cube & 9 & 43 & 319 \\
\hline 6 & Es dalam plastik/lce in plastic & 44 & 1 & 49 \\
\hline 7 & Umpan/Bait & 95 & 4 & 475 \\
\hline 8 & Garam/Salt & 6 & 5 & 27 \\
\hline B. & Biaya Perbekalan Melaut/Sea Supply Cost & & & 363 \\
\hline 1 & Beras/Rice & 5 & 11 & 55 \\
\hline 2 & Kopi/ Coffee & 2 & 7 & 11 \\
\hline 3 & The/Tea & 2 & 6 & 8 \\
\hline 4 & Mie instan/Instantnoodles & 14 & 7 & 53 \\
\hline 5 & Rokok/Cigarete & 7 & 21 & 131 \\
\hline 6 & Telur/Egg & 3 & 19 & 25 \\
\hline 7 & Ikan asin/Saltedfish & 1 & 23 & 12 \\
\hline 8 & Minyak goreng/Cooking oil & - & 14 & 17 \\
\hline 9 & Biskuit dan makanan ringan/Snacks & - & 24 & 21 \\
\hline 10 & Obat-obatan/Medicine & - & 5 & 20 \\
\hline 11 & Air bersih/Cleanwater & - & 9 & 10 \\
\hline C. & Biaya Operasional lainnya/Other Operation Cost & & & 120 \\
\hline 1 & Retribusi di TPI/Retribution & - & - & - \\
\hline 2 & Iuran Organisasi/Organizational Fees & 1 & 28 & 28 \\
\hline 3 & $\begin{array}{l}\text { Upah pekerja pembersih kapal/Wages for ship } \\
\text { cleaners }\end{array}$ & - & 70 & 70 \\
\hline 4 & Iuran koperasi/Cooperative contributions & 1 & 22 & 22 \\
\hline 5 & Pungutan keamanan/Security levies & - & - & - \\
\hline 6 & Biaya angkut/ Freight costs & - & - & - \\
\hline \multirow[t]{2}{*}{7} & Biaya tambat labuh/ Mooring costs & - & - & - \\
\hline & Jumlah/Total & & & $2,166,000$ \\
\hline
\end{tabular}

Sumber: BBRSEKP, 2018/Source: BBRSEKP, 2018. 
Tarakan dan perairan Sebatik (Suryandari, Hedianto \& Tjahjo, 2018; Tirtadanu, Suprapto \& Pane. 2018). Perairan Sebatik merupakan salah satu daerah penangkapan utama udang windu di Wilayah Pengelolaan Perikanan (WPP) 716.

Hasil tangkapan nelayan di Pulau Sebatik antara lain ikan pelagis, udang dan moluska yang memiliki nilai ekonomis tinggi dengan komposisi ikan tenggiri sebesar $17 \%$ senilai 1,70 juta rupiah, udang sekitar $10 \%$ senilai 1,05 juta rupiah, kakap merah sebesar $10 \%$ senilai 1,02 juta rupiah, ikan perak, yaitu sebesar $7,06 \%$ atau rata-rata senilai Rp709.000, dan ikan putih senilai $6 \%$ senilai Rp632.000.
Dilihat dari sisi harga, udang dan moluska yang mempunyai harga tertinggi yaitu Rp155.000/kg untuk udang windu dan, Rp80.000/ $\mathrm{kg}$ untuk ikan perak, ikan bawal (Rp79.000/kg untuk ikan bawal, Rp73.000/kg untuk udang dan Rp57.000/kg untuk kakap merah. Sedangkan dilihat dari hasil tangkapan nelayan berdasarkan volume, yang paling banyak tertangkap adalah jenis udang dan moluska (Tabel 3 ), secara berturutturut yaitu ikan tenggiri $(44,6 \mathrm{~kg})$, ikan parang $(27,3 \mathrm{~kg})$, ikan pari $(26,5 \mathrm{~kg})$, ikan puput $(25,5 \mathrm{~kg})$, dan ikan ode $(23,1 \mathrm{~kg})$. Faktor yang mempengaruhi pendapatan nelayan adalah banyaknya tenaga kerja, teknologi penangkapan, lama melaut dan harga bahan bakar minyak (Darfiana, 2019).

Tabel 3. Pendapatan Rata-Rata Nelayan Per Trip Terakhir di Pulau Sebatik Kabupaten Nunukan Tahun 2018.

Table 3. Fishers' income per last-trip in Sebatik Island, Nunukan Regency, 2018.

\begin{tabular}{|c|c|c|c|c|c|}
\hline No & $\begin{array}{l}\text { Sumber Pendapatan/ } \\
\text { Source of Income }\end{array}$ & $\begin{array}{l}\text { Volume }(\mathrm{Kg}) / \\
\text { Volumes }(\mathrm{Kg})\end{array}$ & $\begin{array}{c}\text { Harga per Satuan } \\
\text { (Rp/Kg)/Price per } \\
\text { Unit (IDR/Kg) }\end{array}$ & $\begin{array}{l}\text { Nilai (Rp)/ } \\
\text { Value (IDR) }\end{array}$ & (\%) \\
\hline A & Jenis Ikan/FishTypes & & & & \\
\hline 1 & Arut/Baredjavelin & 10.5 & $38 ., 526$ & 419,636 & 4.18 \\
\hline 2 & Bawal/Pomfret & 6.3 & 79.,333 & 492,968 & 4.19 \\
\hline 3 & Bandeng/Milkfish & 1.1 & $28 ., 000$ & 30,800 & 0.31 \\
\hline 4 & Bulan/Oxeyeherring & 6.1 & $11 ., 792$ & 48,751 & 0.49 \\
\hline 5 & Cakalang/Skipjack & 17.2 & $27 ., 313$ & 238,675 & 2.38 \\
\hline 6 & Senangin/Fourfingerthreadfin & 14.6 & $31 ., 115$ & 533,726 & 5.32 \\
\hline 7 & Ose/Catfishess & 23.1 & $10 ., 717$ & 345,804 & 3.45 \\
\hline 8 & Ote/Catfishess & 20.8 & $3 ., 966$ & 83,724 & 0.83 \\
\hline 9 & Pari/Rays & 26.5 & 6.,702 & 141,420 & 1.41 \\
\hline 10 & Pani/Yellow tailking fish & - & - & - & - \\
\hline 11 & Puput/Chineseherring & 25.5 & 7,463 & 293,066 & 2.92 \\
\hline 12 & Putih/Whitefish & 18.6 & 32,271 & 631,828 & 6.30 \\
\hline 13 & Perak/Hase & 10.0 & 80,125 & 708,761 & 7.06 \\
\hline 14 & Parang/Wolf-herring & 27.3 & 31,990 & 173,820 & 1.73 \\
\hline 15 & Sebelah/Sole & 7.8 & 20,625 & 145,688 & 1.45 \\
\hline 16 & Tuna/Tuna & 5.0 & 30,000 & 150,000 & 1.50 \\
\hline 17 & Tenggiri/Mackerel & 44.6 & 34,717 & $1,695,572$ & 16.90 \\
\hline 18 & Teri/Anchovy & - & - & - & - \\
\hline 19 & Talang/Talang & 17.1 & 11,237 & 238,451 & 2.38 \\
\hline 20 & Tude/Tude & 3.0 & 55,000 & 165,000 & 1.64 \\
\hline 21 & Kerapu/Grouper & 11.5 & 51,433 & 616,709 & 6.15 \\
\hline 22 & Senangin/Kurau & 9.7 & 50,000 & 483,333 & 4.82 \\
\hline 23 & Kakap Merah/Red Grouper & 17.7 & 57,359 & $1,016,710$ & 10.13 \\
\hline B & $\begin{array}{l}\text { Jenis Udang dan Moluska/ } \\
\text { Shrimpand Mollusc Types }\end{array}$ & & & & \\
\hline 1 & Lobster/Lobsters & 2.5 & 155,000 & 325,500 & 3.24 \\
\hline 2 & Udang/Shrimp & 16.0 & 72,995 & $1,053,010$ & 10.50 \\
\hline \multirow[t]{2}{*}{3} & Kepiting/Crab & - & - & - & - \\
\hline & Total & & & $10,032,952$ & 100.00 \\
\hline
\end{tabular}

Sumber: BBRSEKP, 2018/Source: BBRSEKP, 2018 


\section{PERKEMBANGAN..PEMASARAN..DAN DISTRIBUSI PERIKANAN}

Produksi perikanan tangkap di Kabupaten Nunukan didominasi oleh ikan demersal dan pelagis. Jenis ikan yang memberikan kontribusi terbesar adalah ikan tenggiri, ikan kakap, ikan perak, dan ikan putih. Pasar terbesar untuk ikan dari Nunukan adalah Tawau Negara Bagian Sabah Malaysia. Jenis ikan yang dipasarkan ke Tawau mayoritas adalah ikan demersal dalam bentuk ikan segar, krustasea dan bandeng (tambak). Sementara untuk konsumsi lokal di Sebatik, pedagang ikan mengimpor ikan pelagis kecil dari Tawau.

Pemasaran ikan dari Pulau Sebatik melibatkan pedagang pengumpul dan pedagang besar yang mempunyai agen di Tawau dan mempunyai ikatan sosial dan ekonomi. Jumlah pedagang pengumpul dan pedagang besar yang tercatat di Pulau Sebatik kurang lebih antara 24-30 orang. Pedagang ikan di Kabupaten Nunukan mempunyai jalur pemasaran yang dapat dibedakan menjadi dua yaitu perdagangan ikan demersal dan ikan pelagis. Produksi ikan demersal nelayan Kabupaten Nunukan dipasarkan melalui toke dan selanjutnya dijual untuk konsumsi lokal (11\%) dan ekspor ke Tawau (89\%). Dengan demikian, nilai tambah produksi perikanan Sebatik tidak diperoleh masyarakat Sebatik. Dinamika perekonomian masyarakat di Sebatik sangat bergantung pada kondisi perekonomian di Tawau, Malaysia. Barang-barang yang dikonsumsi masyarakat Sebatik banyak yang diimpor dari Tawau, begitu juga dengan barang elektronik, dan gas (Siburian, 2012).

Selain mengekspor ikan demersal, pedagang pengumpul (toke) membeli ikan pelagis kecil dengan harga yang lebih murah dan dijual kembali untuk memenuhi kebutuhan konsumsi lokal di Pulau Sebatik. Pedagang pengumpul (toke) Pulau Sebatik memasarkan ikan pelagis kecil ke pasar ikan dan pedagang pengecer. Selanjutnya dari pedagang di pasar, ikan dikonsumsi dan dimanfaatkan oleh rumah makan dan rumah tangga. Selanjutnya, pedagang pengecer akan menjual ke pasar ikan, rumah makan dan rumah tangga. Di lain pihak, toke Pulau Sebatik yang membeli ikan pelagis kecil dari Tawau memasarkan ikannya melalui pedagang pengecer motor dan sepeda. Pedagang pengecer motor dan sepeda memasarkan ke konsumen akhir yaitu rumah tangga dan rumah makan. Kurnia, (2017) menyatakan adanya hubungan ekonomi dalam hal perikanan dapat meningkatkan kesejahteraan masyarakat Pulau Sebatik seperti tingginya harga ikan demersal yang dijual di Tawau, Malaysia.

Berdasarkan Kementerian Kelautan dan Perikanan (2017) dan arah pembangunan ekonomi dan bisnis di Kalimantan seperti pada Sekretariat Kabinet RI (2011), maka program pembangunan harus memberikan keuntungan yang optimal dalam

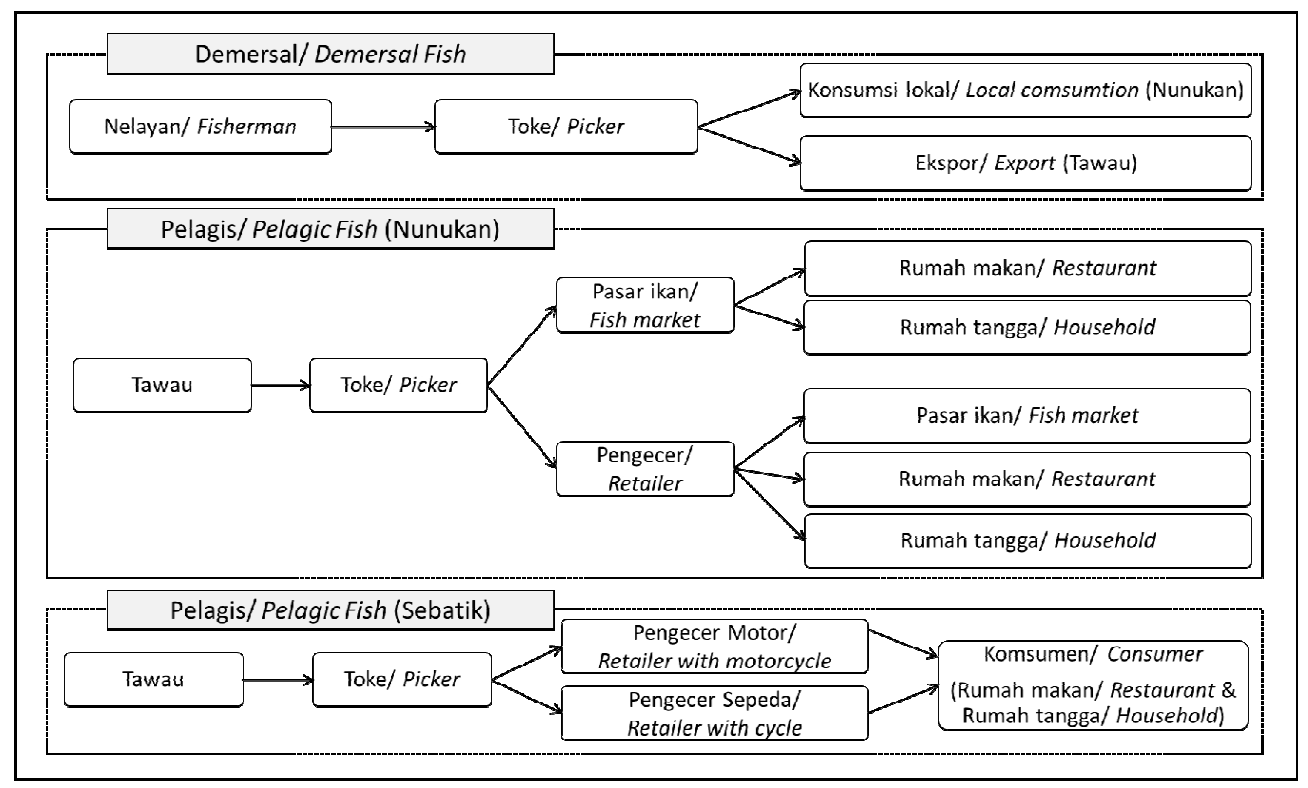

Gambar 4. Alur Pemasaran Sumberdaya Ikan di Sebatik - Tawau.

Figure 4. Flow Marketing of Fishery Resources in Sebatik - Tawau.

Sumber: Hasil Wawancara Diolah/Source: Interview Results Processed 
perekonomian (Hadi, 2007 dan Suriadikarta, 2000). Selain itu juga infrastruktur yang dibangun sesuai dengan kebutuhan masyarakat (Hadi, 2009). Pembangunan SKPT Sebatik dianggap perlu karena akan berdampak pada percepatan industri perikanan, sekaligus mendorong perekonomian pulau terluar di Indonesia, seperti Pulau Sebatik.

Pelaku usaha perikanan di Pulau Sebatik dapat memanfaatkan Pusat Bisnis di Sentra Kelautan dan Perikanan Terpadu (SKPT) Sebatik untuk mendukung kegiatan usaha perikanannya. Peran Pemerintah Pusat dan Pemerintah Daerah sangat diperlukan untuk mendukung kegiatan dan operasionalisasi Pusat bisnis dilokasi SKPT Sebatik sebagai pintu keluar-masuknya hasil dan produk perikanan dianggap perlu untuk menghindari IUU Fishing di Pulau Sebatik dan sekitarnya. Pembangunan SKPT Sebatik juga diperlukan dalam rangka untuk percepatan industri perikanan dan sekaligus untuk mendorong pertumbuhan ekonomi di pulau-pulau terluar khususnya Pulau Sebatik.

Pemerintah pusat dan daerah membangun SKPT Sebatik dengan berbagai sarana dan prasarana serta membuat berbagai kebijakan pendukung. Lokasi SKPT Sebatik ini menjadi pusat aktivitas ekonomi dan pelayanan bisnis perikanan di Sebatik, sebagai sarana menghimpun hasil tangkapan ikan, penanganan dan pengolahan ikan, distribusi dan perdagangan ikan. Untuk itu, SKPT Sebatik perlu peningkatan pengawasan oleh PSDKP untuk mengurangi armada kapal asing maupun dalam negeri yang menggunakan alat tangkap tidak ramah lingkungan seperti trawl.

\section{IMPLIKASI KEBIJAKAN}

Keberadaan nelayan tangkap di Pulau Sebatik saat ini masih berada pada tangkahantangkahan kecil dan perlu diintegrasikan ke dalam pusat bisnis SKPT Sebatik. Integrasi ini diperlukan sebagai langkah awal dalam pendataan dan legalisasi ekspor perikanan ikan karang dari Pulau Sebatik ke Tawau sehingga nilai ekonomi dari perdagangan perikanan tercatat sebagai ekspor Indonesia.

\section{UCAPAN TERIMA KASIH}

Terima kasih diucapkan kepada semua pihak yang telah membantu kegiatan penelitian ini, terutama tim peneliti dalam kegiatan "Riset Model Integrasi Ekonomi dalam Mendukung Percepatan
Industrialisasi Perikanan Nasional di Lokasi SKPT (Nunukan)" oleh Balai Besar Riset Sosial Ekonomi Kelautan dan Perikanan (BBRSEKP). Semoga tulisan ini dapat dijadikan sebagai bahan pertimbangan untuk perbaikan kebijakan industrialisasi perikanan nasional pada waktu yang akan datang.

\section{PERNYATAAN KONTRIBUSI PENULIS}

Asnawi dan Firsta Kusuma Yudha sebagai kontributor utama, dan Umi Muawanah sebagai kontributor anggota dalam karya tulis ilmiah ini merancang penelitian, melakukan pengambilan data di lapangan, dan analisis data, serta menulis manuskrip. Seluruh penulis bersama-sama mendesain penelitian, mengumpulkan data di lapangan, dan meninjau naskah.

\section{DAFTAR PUSTAKA}

Balai Besar Riset Sosial Ekonomi Kelautan dan Perikanan (BBRSEKP). (2018). Riset model integrasi ekonomi dalam mendukung percepatan industrialisasi perikanan di lokasi SKPT Nunukan. Laporan Riset. Jakarta

BPS Kabupaten Nunukan. (2017). Kabupaten Nunukan dalam angka 2016. Nunukan : BPS Nunukan

Darfiana, D. (2019). Faktor-faktor yang mempengaruhi pendapatan Nelayan di Desa Tanjung Harapan Kecamatan Sebatik Timur (Doctoral dissertation). Universitas Islam Negeri Alauddin, Makassar

Dinas Kelautan dan Perikanan Kabupaten Nunukan. (2015). Statistik kelautan dan perikanan Kabupaten Nunukan tahun 2014. Nunukan: Dinas Kelautan dan Perikanan Kabupaten Nunukan. Pemerintah Kabupaten Nunukan

Ghafur, M. F. (2016). Ketahanan sosiaal di perbatasan: Studi kasus Pulau Sebatik. Jurnal Masyarakat Indonesia, 42(2): 233-247. Retrivied from: http://jmi.ipsk.lipi.go.id/index.php/jmiipsk/article/ view/669

Ghafur, M. F. (2018). Ketahanan Sosial Masyarakat di Perbatasan: Studi Kasus di Pulau Sebatik. Masyarakat Indonesia, 42 (2), 233-247

Hadi, K. (2007). Petani Dayak: Pengusaha tanpa Perusahaan. Majalah Kalimantan Review. No.145/Thn XVI/September

Hadi, K. (2009). Kebijakan program mamanguntuntangmahaga lewu di kalimantanTengah. Jurnal IImu - IImu Sosial Alternatif. Vol:X(1). DOI: https:// doi.org/10.22219/jep.v11i1.3734

Husin, S. R. B. (2018). Identifikasi Alat Penangkapan Ikan Di di Pulau Sebatik, Kabupaten Nunukan, 
Kalimantan Utara. [skripsi]. Universitas Hasanudin

Juzmi, A. N., Triarso, I., \& Fitri, A. D. P. (2017). Analisis tingkat kesejahteraan nelayan pemilik dan buruh pada perikanan mini purseseine di PPP Lempasing Bandar Lampung. Journal of Fisheries Resources Utilization Management and Technology, Vol 6(4), 252-258. Retrieved from: https://ejournal3.undip.ac.id/index.php/jfrumt/ article/view/18897

Kementerian Kelautan dan Perikanan. (2017). Keputusan Menteri Nomor. KEP.50/KEPMEN-KP/2017 tentang Estimasi Potensi Sumber Daya Ikan di Wilayah Pengelolaan Perikanan Negara Republik Indonesia. Jakarta: Kementerian Kelautan dan Perikanan

Kurnia, M. P. (2017). Strategi optimalisasi perdagangan lintas batas Indonesia-Malaysia untuk meningkatan kesejahteraan masyarakat Pulau Sebatik Kabupaten Nunukan. Jurnal Supremasi, Vol 7(1), 1-14. DOI: https://doi. org/10.35457/supremasi.v7i1.372

Mansur, T. M., Muazzin, M., Yani, T. A., \& Sulaiman, S. (2017). Pengaturan hukum perlindungan nelayan kecil. Kanun: Jurnal IImu Hukum, Vol 19(3), 383-397. Retrieved from: http://www.jurnal. unsyiah.ac.id/kanun/article/view/8982

Mira, M., Solihin, A., \&Tajerin, T. (2017). Strategi peningkatan ekonomi wilayah perbatasan berbasis kelautan Dan dan perikanan (studi kasus di Nanusa, Natuna dan Nunukan). Sosio Konsepsia, Vol 2(3), 255-278. DOI: https://doi. org/10.33007/ska.v2i3.780

Mirnawati, M., Nelwan, A. F., \& Zainuddin, M. (2019). Studi tentang komposisi jenis hasil tangkapan purseseine berdasarkan lokasi penangkapan di Perairan Tanah Beru Kecamatan Bonto Bahari Kabupaten Bulukumba. Jurnal IPTEKS Pemanfaatan Sumberdaya Perikanan, Vol 6(11). DOI: https://doi.org/10.20956/jipsp.v6i11.6274

Najamuddin, N., Hajar, M. A. I., \& Sarira, M. (2018). Analisis unit penangkapan ikan pelagis di Kabupaten Pinrang. Jurnal IPTEKS Pemanfaatan Sumberdaya Perikanan, 4(7). DOI: DOI: https:// doi.org/10.20956/jipsp.v4i7.3136

Nikijuluw, V. P. (2002). Rezim pengelolaan sumberdaya perikanan. Cetakan 1. Jakarta : Kerja sama Pusat Pemberdayaan dan Pembangunan Regional (P3R) dengan PT. Pustaka Cidesindo

Nurisnaeny, P. S. (2012). Adaptasi nelayan kawasan perbatasan di Desa Sei Pancang Kecamatan Sebatik Utara Kabupaten Nunukan Provinsi Kalimantan Utara. Jurnal Communicate, Vol 1 (2): 55-66. DOI: http://dx.doi.org/10.31479/jc.v1i2.37

Poerwandari, E. K. (2005). Pendekatan Kualitatif Untuk Penelitian Perilaku Manusia.(ed-3), Jakarta: Perfecta LPSPS. Fakultas Psikologi UI
Radiarta, N., Erlania, E., Haryadi, J., \& Rosdiana, A. (2016). Analisis pengembangan budidaya rumput laut di Pulau Sebatik, Kabupaten Nunukan, Kalimantan Utara. Jurnal Kebijakan Perikanan Indonesia, 8(1), 29-40. DOI: http://dx.doi. org/10.15578/jkpi.8.1.2016.29-40

Sekretariat Kabinet RI. (2011). Perpres Peraturan Presiden Nomor 32 Tahun 2011 tentang Masterplan Percepatan dan Perluasan Pembangunan Ekonomi Indonesia (MP3El) 2011-2025. 20 Mei 2011. Jakarta : Sekretariat Kabinet RI

Setiawan, B., S. Bandiyono., Sudiyono,\& M. Soekarni. (2011). Kompleksistas Pembangunan dan Strategi Pemberdayaan Keluarga di Perbatasan Sebatik. Jakarta, ID : Pusat Penelitian Kependudukan LIPI \& Elmatera Publisher

Shafitri, N., Zulham, A., \& Muawanah, U. (2020). Masyarakat Pesisir dan Perilakunya Terhadap Jaringan Usaha Perikanan: Studi Kasus Daerah Perbatasan di Kabupaten Nunukan. Buletin IImiah Marina Sosial Ekonomi Kelautan dan Perikanan, 6(1). DOI: http://dx.doi.org/10.15578/ marina.v6i1.8721

Siburian, R. (2012). Pulau Sebatik: Kawasan perbatasan Indonesia beraroma Malaysia. Jurnal Masyarakat dan Budaya, Vol (14) 1, 53-75. DOI: https://doi. org/10.14203/jmb.v14i1.87

Solihin, A., Imron, M., \& Wahyono, A. (2012). "Baganisasi" di Perairan Pulau Sebatik dalam mengatasi illegal fishing ("Baganisasi" in the Sebatik Island Waters on combating illegal fishing). Buletin PSP, 20(2), 205-211. Retrieved from: https://jurnal.ipb.ac.id/ index.php/bulpsp/article/view/6245

Solihin, I., Wisudo, S. H., Haluan, J., \& Martianto, D. (2011). Pengembangan Produksi Perikanan Tangkap di Wilayah Perbatasan (Kasus Kabupaten Nunukan Kalimantan Timur. Buletin PSP, 19 (2)

Suriadikarta, D.A. (2009). Pembelajaran dari kegagalan penanganan kawasan PLG sejuta hektar menuju pengelolaan lahan gambut berkelanjutan. Pengembangan Inovasi Pertanian, Vol 2(4), 229-242

Suryandari, A., Hedianto, D. A., \& Tjahjo, D. W. H. (2018). Karakteristik biologi dan daerah asuhan udang windu (Penaeus monodon Fabricius, 1798) di perairan Aceh Timur. Jurnal Penelitian Perikanan Indonesia, Vol 24(2), DOI: http:// dx.doi.org/10.15578/jppi.24.2.2018.105-116

Tirtadanu, Suprapto, \& Pane, A. R. (2018). Komposisi jenis, sebaran dan kepadatan stok udang pada musim selatan di perairan Timur Kalimantan. BAWAL, Vol 10(1), DOI: http://dx.doi. org/10.15578/bawal.10.1.2018.41-47 